\title{
Recommendations for the Shear Assessment of Reinforced Concrete Slab Bridges from Experiments
}

\author{
Eva Olivia Leontien Lantsoght, Dr.; Cor van der Veen, Dr.; Joost Walraven, Prof.; Delft University of Technology, Civil \\ Engineering and Geosciences - Design \& Construction-Concrete Structures, Delft, The Netherlands; Ane de Boer, Dr.; \\ Ministry of Infrastructure and the Environment, Utrecht, The Netherlands. Contact: E.O.L.Lantsoght@tudelft.nl
} DOI: $10.2749 / 101686613 X 13627347100239$

\begin{abstract}
Upon assessment of existing reinforced concrete short-span solid slab bridges according to the recently implemented Eurocodes that include more conservative shear capacity provisions and heavier axle loads, a number of these structures were found to be shear-critical. The results from recent experimental research on the shear capacity of slabs indicate that slabs benefit from transverse load distribution. Recommendations for the assessment of solid slab bridges in shear are developed on the basis of these experiments. A load spreading method for the concentrated loads is proposed and the applicability of superposition of loading is studied. The resulting most unfavourable position for the design trucks is provided and implemented in the so-called Dutch "Quick Scan" method (QSEC2). Cases of existing bridges are studied with the previously used QS-VBC as well as with the QS-EC2 that includes the recommendations. As a result of the assumed transverse load distribution, the shear stress to be considered at the support based on the recommendations becomes smaller.
\end{abstract}

Keywords: effective width; live loads; load distribution; reinforced concrete; slab bridges; shear.

\section{Introduction}

A large number of the Dutch existing reinforced concrete bridges in the road network are short-span solid slab bridges, $60 \%$ of which have been built before 1975 . Since then, the traffic loads have increased significantly, resulting in heavier live load models in NEN-EN 1991-2:2003. ${ }^{1}$ Also, the shear capacity as prescribed by the codes is more conservative in the recently implemented NEN-EN 1992-1-1:2005² than in the Dutch NEN 6720:1995. ${ }^{3}$ As a result, 600 slab bridges are found to be shear-critical when assessed with the Eurocodes. Upon inspection, these bridges did not show signs of distress. ${ }^{4,5}$ This indicates that slab bridges possess additional sources of bearing capacity that are not taken into account in the concrete design codes. In slabs, one of the major sources of additional capacity is the slab's ability for transverse load distribution.

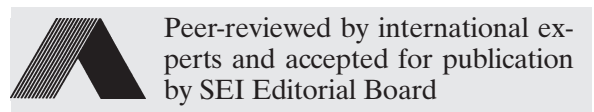

Paper received: January 28, 2013

Paper accepted: April 1, 2013
The shear capacity as prescribed by NEN $6720^{3}$ and NEN-EN 1992-1-1 ${ }^{2}$ is determined from a statistical analysis of experiments on relatively small, heavily reinforced concrete beams loaded in four-point bending. ${ }^{6}$ When these expressions are applied to determine the shear capacity of a slab under a concentrated load, the contribution of the surrounding material, which is activated through transverse load distribution, is not taken into account. Moreover, the effective width in shear for slabs under a concentrated load needs to be determined. In practice, the effective width is based on a load spreading method:

1. from the centre of the load towards the face of the support as used in Dutch practice (Fig. 1a), resulting in $b_{\text {eff } 1}$; or

2. from the far side of the load towards the face of the support as used in French practice ${ }^{7}$ (Fig. 1b), resulting in $b_{\text {eff2 }}$.

To quantify the enhancement due to transverse load distribution in slabs under a concentrated load in shear, a comprehensive series of experiments was carried out. ${ }^{8-10}$ In a first series of experiments, 18 slabs and 12 slab strips were tested under a concentrated load near the support. In a second series, eight additional slabs were tested under a combination of a concentrated load near the support and a line load. These experiments form the basis for new recommendations for the shear assessment of slab bridges. In sections Experiments and Recommendations, the link between these experiments and the recommendations is discussed.

The large number of solid slab bridges that are identified as shear-critical require a systematic approach. In a preliminary general assessment, the database of slab bridges was screened in order to identify the particular bridges that require a more detailed analysis. For this purpose, a fast, simple and conservative tool is required: the "Quick Scan" method (QS-EC2). The first "Quick Scan" sheets were developed by Dutch engineering firms for the Ministry of Infrastructure and the Environment in the mid-2000s. The output of these spreadsheets is a "Unity Check" (UC) value: the ratio between the design value of the applied shear stress resulting from the loads (dead loads and live loads) and the shear resistance. The wheel loads should be placed in such a way that the maximum shear stress is found near the edge of the support because a high shear stress near the edge is determined to be a more critical case for the development of a shear crack than in the middle of the width. ${ }^{11}$

\section{Loads for Assessment}

\section{Live Load Model from Eurocode 1}

The shear stress in a slab bridge at the support results from the action of dead loads (self-weight of the structure and the wearing surface) and live loads. NEN-EN 1991-2 ${ }^{1}$ Load Model 1 is used for assessment. This load model (Fig. 2) combines design trucks with a design lane load that is heavier on the first, slow lane. The design truck has 


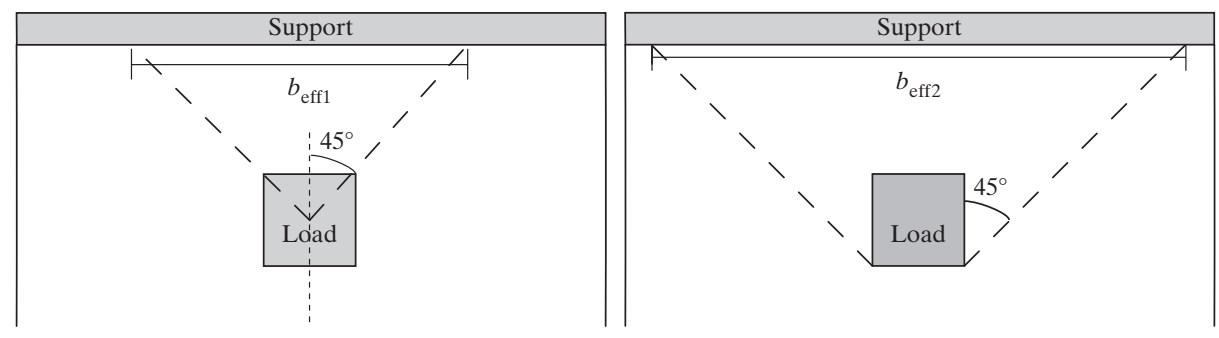

Fig. 1: Horizontal load spreading between concentrated load and support (top view of slab): (a) load spreading from the centre of the load as used in Dutch practice, and (b) load spreading from the far side of the load as used in French practice

(a)

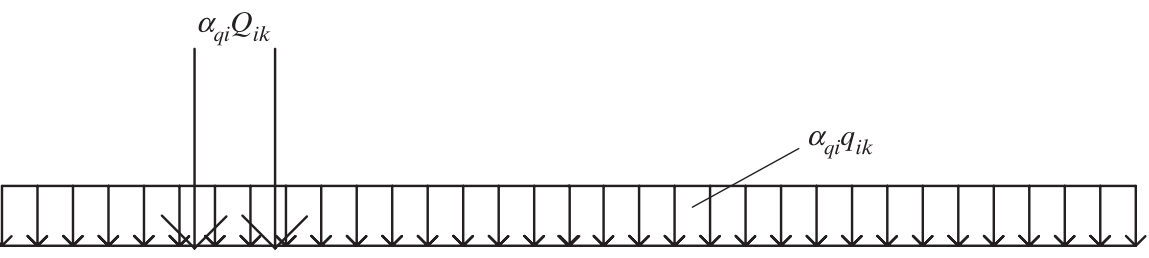

(b)

$1,2 \mathrm{~m}$

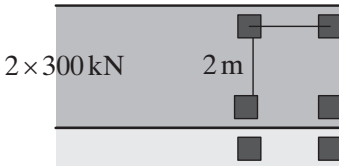

$2 \times 200 \mathrm{kN}$

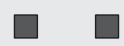

$2 \times 100 \mathrm{kN}$

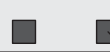

$400 \times 400 \mathrm{~mm}$

Fig. 2: NEN-EN 1991-2:20031 Load Model 1 (a) side view; (b) top view

a tyre contact area of $400 \times 400 \mathrm{~mm}^{2}$ and an axle load of $\alpha_{Q 1} \times Q_{1 k}$ $=\alpha_{Q 1} \times 300 \mathrm{kN}$ in the first lane, $\alpha_{Q 2} \times Q_{2 k}=\alpha_{Q 2} \times 200 \mathrm{kN}$ in the second lane and $\alpha_{Q 3} \times Q_{3 k}=\alpha_{Q 3} \times 100 \mathrm{kN}$ in the third lane. The values of $\alpha_{Q i}=1$ for the Netherlands. The lane load is applied over the full notional lane width $(3 \mathrm{~m})$ and equals $\alpha_{q 1} \times q_{1 k}=\alpha_{q 1} \times 9 \mathrm{kN} / \mathrm{m}^{2}$ for the first lane and $\alpha_{q i} \times q_{i k}=\alpha_{q i} \times 2,5 \mathrm{kN} / \mathrm{m}^{2}$ for all other lanes. In the Dutch National Annex, for bridges with three or more notional lanes, the value of $\alpha_{q 1}$ equals $\alpha_{q 1}=1,15$ and for $i>1$ the value can be taken as $\alpha_{q i}=1,4$.

\section{Safety Levels}

The Eurocode suite is applicable for the design of structures, but guidelines for the assessment of existing structures are not yet available. For assessment according to the basic assumptions and safety philosophy of the Eurocodes, in the Netherlands a set of national codes (NEN 8700:2011 ${ }^{12}$ for the basic rules, NEN 8701:2011 ${ }^{13}$ for actions, etc.) is developed. The safety requirements for an existing structure are smaller than for newly designed structures, and as a result, a different set of load factors can be used. The two safety levels described in NEN 8700:2011 ${ }^{12}$ are the "repair" level with a reliability index 3,8 $<\beta_{\text {rel }} \leq 3,3$ (and 3,6 for structures built before 2012) and the "unfit for use" level with $\beta_{\text {rel }}<3,3^{14}$ for consequences class 3 (bridges) from NEN-EN 1990:2002. ${ }^{15}$ The load factors associated with the "repair" level are $\gamma_{\mathrm{DL}}=1,15$ for dead loads and $\gamma_{\mathrm{LL}}=1,3$ for live loads for structures built before 2012. The material factors remain unaltered.

\section{Experiments}

\section{Test Setup}

To improve the assessment of slab bridges under live loads, the contribution of the transverse load distribution and effective width need to be determined. For this purpose, a series of experiments is executed on a halfscale model of a continuous reinforced concrete slab bridge. The test program consists of 26 slabs (S-series) of $5 \times 0,3 \times 2,5 \mathrm{~m}^{3}$ and 12 slab strips (B-series) of $5 \times 0,3 \mathrm{~m}^{2}$ with a variable width on which a total of 156 experiments are carried out. A top view of the test setup is presented in Fig. 3. The support conditions are varied: slabs on line supports (S1-S14), three elastomeric bearings per support (S15-S18) or seven bearings per support (elastomeric: S23-S24 or steel: S19-S22, S25S26). S1 to S18 and all slab strips (BS1 to BX3) are tested with a concentrated load only; S19-S26 are tested under a combination of a concentrated load and a line load of $240 \mathrm{kN} / \mathrm{m}$ at $1,2 \mathrm{~m}$ from the support. Experiments are carried out close to the simple support (sup 1, SS in Fig. 3a) and the continuous support (sup 2, CS in Fig. 3a), where the rotation is partially restrained by vertical pre-stressing bars. The concentrated load is placed at different positions along the span of the slab and at different positions along the width: in the middle ("M" in Fig. 3a) and near the edge of the slab ("E" in Fig. 3a).

\section{Specimens}

All specimens are cast at Delft University of Technology with concrete mixtures as delivered by an external company. During each cast, two identical specimens are made. The following parameters are varied: the amount of transverse flexural reinforcement $\rho_{t}(0,132 \%$, Fig. 3c; $0,182 \%$, Fig. $3 d$ and $0,258 \%$, Fig. $3 e$ ), the concrete compressive strength (normal strength concrete $\mathrm{C} 28 / 35$ and high strength concrete $\mathrm{C55/65)}$ ), plain bars as compared to deformed bars and, in the B-series, the overall specimen width $b(\mathrm{BS} / 0,5 \mathrm{~m}, \mathrm{BM} / 1 \mathrm{~m}, \mathrm{BL} / 1,5 \mathrm{~m}$ and $\mathrm{BX} / 2 \mathrm{~m})$. All specimens have a crosssectional depth $h$ of $300 \mathrm{~mm}$. Slabs S1 to S14 and S19 to S26 and all slab strips BS1 to BX3 have an effective depth to the main flexural reinforcement $d_{1}$ of $265 \mathrm{~mm}$. Slabs S15 to S18 have an effective depth $d_{1}$ of $255 \mathrm{~mm}$, as increased cover was required for the virtual beam in the transverse direction above the support. The virtual beam of reinforcement over the support line is necessary for the slabs supported by bearings to create one-way load carrying behaviour. Deformed bars of steel S500 (measured properties for $\phi 20$ : $f_{\mathrm{ym}}=542 \mathrm{MPa}$ yield strength; $f_{\mathrm{um}}=658$ $\mathrm{MPa}$ ultimate strength and for $\phi 10$ : $f_{\text {ym }}=537 \mathrm{MPa} ; f_{\text {um }}=628 \mathrm{MPa}$ ) are used for S1 to S10, S15 to S26 and the slab strips. Plain bars of steel $52.3 \mathrm{~K}$ (measured properties for $\phi 20$ : 
(a)

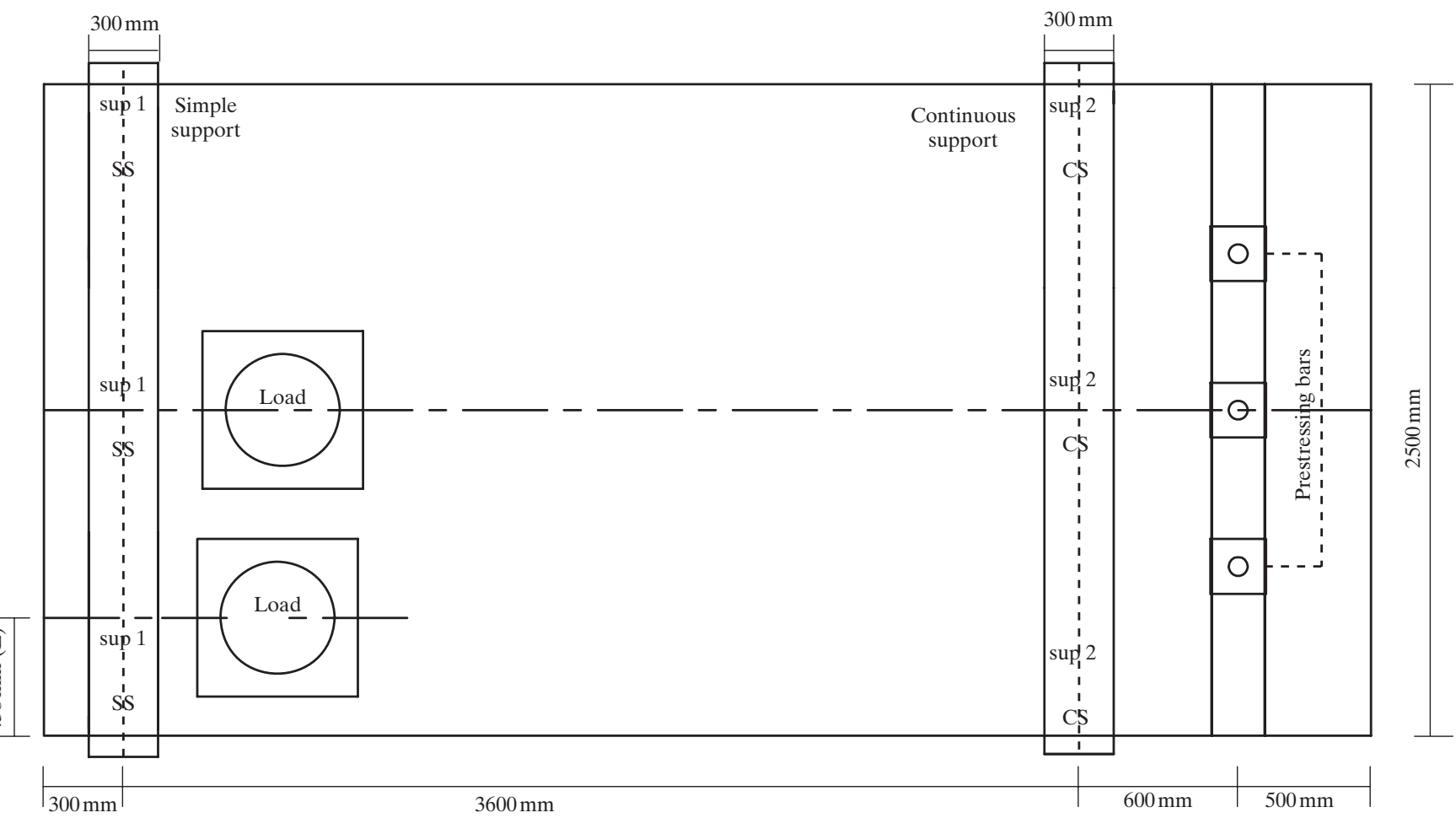

(b)

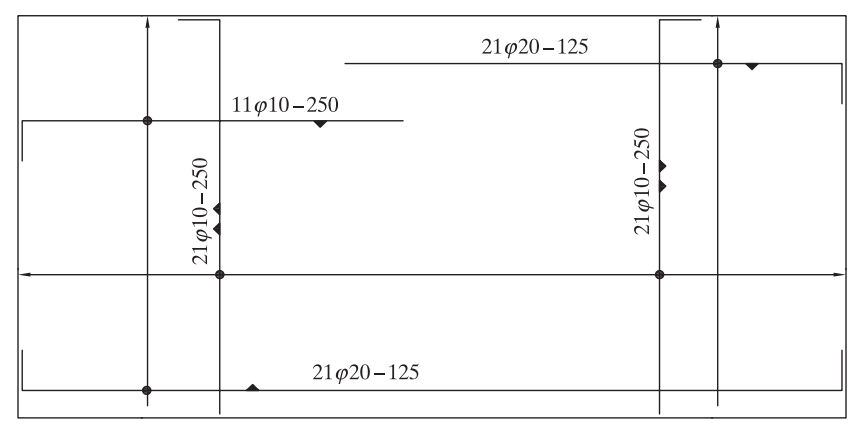

$(f)$

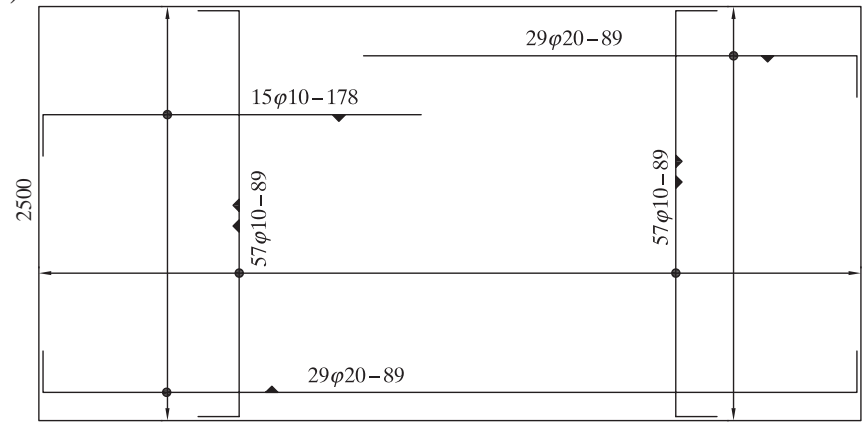

(g)

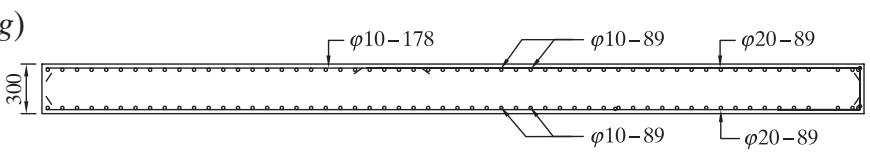

(c)

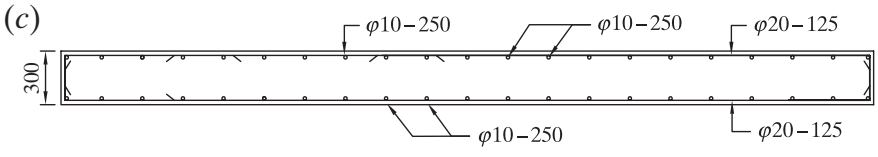

(d)

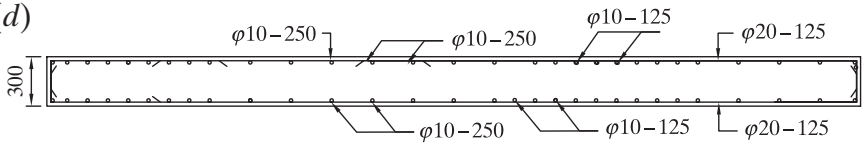

(e)

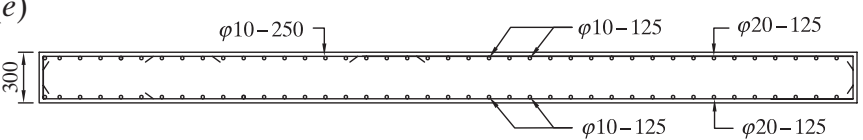

(h)
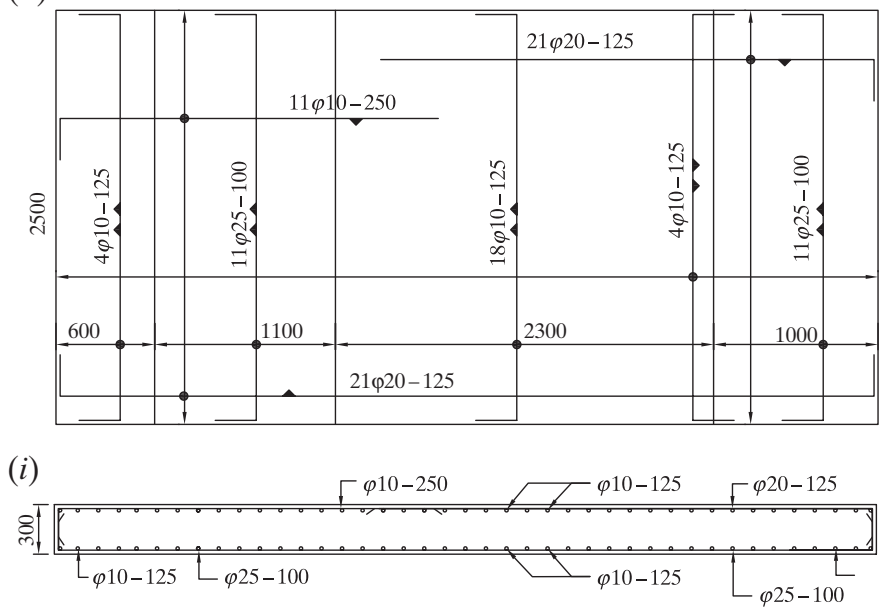

Fig. 3: Experimental setup and specimens: (a) top view of setup, (b) top view and (c) cross section of reinforcement layout for S1, S2; (d) cross section of S4; (e) cross section of S3, S5-S10, S19-S26; (f) top view and (g) cross section of S11-S14; $(h)$ top view and (i) cross section of S15-S18 (Units: $\mathrm{mm}$ )

$f_{\mathrm{ym}}=601 \mathrm{MPa} ; f_{\mathrm{um}}=647 \mathrm{MPa}$ and for $\left.\phi 10: f_{\text {ym }}=635 \mathrm{MPa} ; f_{\text {um }}=700 \mathrm{MPa}\right)$ are used for S11 to S14. A sketch of the reinforcement layout of S1 to S2 is given in Fig. $3 b$ and c; of $\mathrm{S} 4$ in Fig. 3d; of S3, S5 to S10, S19 to S26 in Fig. 3e; of S11 to S14 in Fig. $3 f$ and $g$ and of $\mathrm{S} 15$ to $\mathrm{S} 18$ in Fig. $3 h$ and $i$. The properties of the studied specimens are given in Table 1, with $b$, width of the specimen; $f_{c, \text { meas, }}$ cube compressive strength at the age of testing; $f_{\text {ct,meas, }}$ splitting tensile strength at the age of testing; $\rho_{1}$, amount of longitudinal reinforcement; $\rho_{\mathrm{t}}$, amount of transverse flexural reinforcement; $a / d_{1}$, shear span to depth ratio of the concentrated load; $M / E$, location of the concentrated load 


\begin{tabular}{|c|c|c|c|c|c|c|c|c|c|c|}
\hline Category & Slab no. & $b(\mathrm{~m})$ & $f_{c, \text { meas }}(\mathbf{M P a})$ & $f_{\mathrm{c}, \text { meas }}(\mathrm{MPa})$ & $\rho_{1}(\%)$ & $\rho_{\mathrm{t}}(\%)$ & $a / d_{1}$ & $\mathbf{M} / \mathbf{E}$ & $z_{\text {load }}(\mathrm{mm})$ & Age (days) \\
\hline \multirow{6}{*}{$\begin{array}{l}\text { Normal strength } \\
\text { concrete }\end{array}$} & S1 & 2,5 & 35,8 & 3,1 & 0,996 & 0,132 & 2,26 & $\mathrm{M}$ & 200 & 28 \\
\hline & S2 & 2,5 & 34,5 & 2,9 & 0,996 & 0,132 & 2,26 & $\mathrm{M}$ & 300 & 56 \\
\hline & S3 & 2,5 & 51,6 & 4,1 & 0,996 & 0,258 & 2,26 & $\mathrm{M}$ & 300 & 63 \\
\hline & S4 & 2,5 & 51,7 & 4,2 & 0,996 & 0,182 & 2,26 & $E$ & 300 & 76 \\
\hline & S5 & 2,5 & 48,2 & 3,8 & 0,996 & 0,258 & 1,51 & $\mathrm{M}$ & 300 & 31 \\
\hline & S6 & 2,5 & 50,6 & 3,9 & 0,996 & 0,258 & 1,51 & $\mathrm{E}$ & 300 & 41 \\
\hline \multirow{4}{*}{$\begin{array}{l}\text { High strength } \\
\text { concrete }\end{array}$} & S7 & 2,5 & 82,1 & 6,2 & 0,996 & 0,258 & 2,26 & $\mathrm{E}$ & 300 & 83 \\
\hline & S8 & 2,5 & 77,0 & 6,0 & 0,996 & 0,258 & 2,26 & $\mathrm{M}$ & 300 & 48 \\
\hline & S9 & 2,5 & 81,7 & 5,8 & 0,996 & 0,258 & 1,51 & $M$ & 200 & 77 \\
\hline & S10 & 2,5 & 82,4 & 5,8 & 0,996 & 0,258 & 1,51 & $E$ & 200 & 90 \\
\hline \multirow[t]{4}{*}{ Plain bars } & S11 & 2,5 & 54,9 & 4,2 & 1,375 & 0,358 & 2,26 & $\mathrm{M}$ & 200 & 90 \\
\hline & S12 & 2,5 & 54,8 & 4,2 & 1,375 & 0,358 & 2,26 & $E$ & 200 & 97 \\
\hline & S13 & 2,5 & 51,9 & 4,2 & 1,375 & 0,358 & 1,51 & $\mathrm{M}$ & 200 & 91 \\
\hline & S14 & 2,5 & 51,3 & 4,2 & 1,375 & 0,358 & 1,51 & $E$ & 200 & 110 \\
\hline \multirow{4}{*}{$\begin{array}{l}\text { Elastomeric } \\
\text { bearings }\end{array}$} & S15 & 2,5 & 52,2 & 4,2 & 1,035 & 1,078 & 2,35 & $M$ & 200 & 71 \\
\hline & S16 & 2,5 & 53,5 & 4,4 & 1,035 & 1,078 & 2,35 & $E$ & 200 & 85 \\
\hline & S17 & 2,5 & 52,5 & 3,7 & 1,035 & 1,078 & 1,57 & $M$ & 200 & 69 \\
\hline & S18 & 2,5 & 52,1 & 4,5 & 1,035 & 1,078 & 1,57 & $E$ & 200 & 118 \\
\hline \multirow{8}{*}{$\begin{array}{l}\text { Combination of } \\
\text { loads }\end{array}$} & S19 & 2,5 & 56,9 & 4,7 & 0,996 & 0,258 & 2,26 & $\mathrm{M}$ & 300 & 89 \\
\hline & S20 & 2,5 & 60,5 & 4,7 & 0,996 & 0,258 & 2,26 & $M$ & var & 176 \\
\hline & S21 & 2,5 & 56,8 & 4,5 & 0,996 & 0,258 & 2,26 & $\mathrm{M}$ & 300 & 187 \\
\hline & S22 & 2,5 & 57,8 & 4,5 & 0,996 & 0,258 & 2,26 & $E$ & 300 & 188 \\
\hline & $\mathrm{S} 23$ & 2,5 & 58,9 & 4,7 & 0,996 & 0,258 & 2,26 & $\mathrm{M}$ & 300 & 197 \\
\hline & S24 & 2,5 & 58,9 & 4,7 & 0,996 & 0,258 & 2,26 & $\mathrm{E}$ & 300 & 183 \\
\hline & S25 & 2,5 & 58,6 & 4,5 & 0,996 & 0,258 & var & $M$ & 300 & 170 \\
\hline & S26 & 2,5 & 58,6 & 4,5 & 0,996 & 0,258 & 1,51 & M\&E & 300 & 174 \\
\hline \multirow[t]{12}{*}{ Slab strips } & BS1 & 0,5 & 81,5 & 6,1 & 0,948 & 0,258 & 2,26 & $\mathrm{M}$ & 300 & 55 \\
\hline & BM1 & 1 & 81,5 & 6,1 & 0,948 & 0,258 & 2,26 & $\mathrm{M}$ & 300 & 62 \\
\hline & BL1 & 1,5 & 81,5 & 6,1 & 0,948 & 0,258 & 2,26 & $\mathrm{M}$ & 300 & 189 \\
\hline & BS2 & 0,5 & 88,6 & 5,9 & 0,948 & 0,258 & 1,51 & $\mathrm{M}$ & 200 & 188 \\
\hline & BM2 & 1 & 88,6 & 5,9 & 0,948 & 0,258 & 1,51 & $\mathrm{M}$ & 200 & 188 \\
\hline & BL2 & 1,5 & 94,8 & 5,9 & 0,948 & 0,258 & 1,51 & $\mathrm{M}$ & 200 & 180 \\
\hline & BS3 & 0,5 & 91,0 & 6,2 & \begin{tabular}{|l|}
0,948 \\
\end{tabular} & 0,258 & 2,26 & $\mathrm{M}$ & 300 & 182 \\
\hline & BM3 & 1 & 91,0 & 6,2 & 0,948 & 0,258 & 2,26 & $\mathrm{M}$ & 300 & 182 \\
\hline & BL3 & 1,5 & 81,4 & 6,2 & 0,948 & 0,258 & 2,26 & $\mathrm{M}$ & 300 & 171 \\
\hline & BX1 & 2 & 81,4 & 6,0 & 0,948 & 0,258 & 2,26 & $M$ & 300 & 47 \\
\hline & BX2 & 2 & 70,4 & 5,8 & 0,948 & 0,258 & 1,51 & $\mathrm{M}$ & 200 & 39 \\
\hline & $\mathrm{BX} 3$ & 2 & 78,8 & 6,0 & 0,948 & 0,258 & 2,26 & $M$ & 200 & 40 \\
\hline
\end{tabular}

Table 1: Properties of tested specimens

along the width (Fig. 3a); $z_{\text {load }}$, size of the loading plate; age, age of the specimen at testing.

\section{Summary of Results}

The results of the experiments on slabs are compared to the state-of-the-art with regard to beam shear. ${ }^{10}$ To understand the differences between slabs and beams in shear, and the benefit of transverse load distribution, the main findings of the parameter analysis are summarised in this section.

Reinforced concrete slabs loaded with a concentrated load close to the support show a three-dimensional behaviour that is distinctly different from the two-dimensional shear-carrying behaviour in beams. This observation is represented by the cracking pattern at the bottom of a tested specimen (Fig. $4 a$ and $b$ ). In beams, cracks develop only perpendicular to the span direction, while in slabs the cracks develop perpendicular to and parallel with the span direction, indicating the ability of the slab to distribute the load over the longitudinal and transverse directions. The results of the parameter analysis indicate that the shear capacity of slabs under concentrated loads close to the support depends on the geometrical properties of the slab, the concentrated load and the support.
The distance between the concentrated load and the support has a clear influence on the shear capacity for loads with $a / d_{1}<2,5$. In the experiments, it is observed that this influence becomes less important as the width of the specimen increases. This observation can be explained by compression struts. For beams, a clearly defined strut develops over the distance $a$, while in slabs, a fan of struts can develop by activating the transverse redistribution capacity (Fig. 4c). In beams, only the straight strut $\left(a / d_{1}=1\right.$ in Fig. 4c) can develop. In slabs, a fan of struts and their resulting average load path will result in a larger average $a / d_{1}$ for which a smaller influence on the shear resistance of slabs can be expected, as observed. 
(a)

(b)

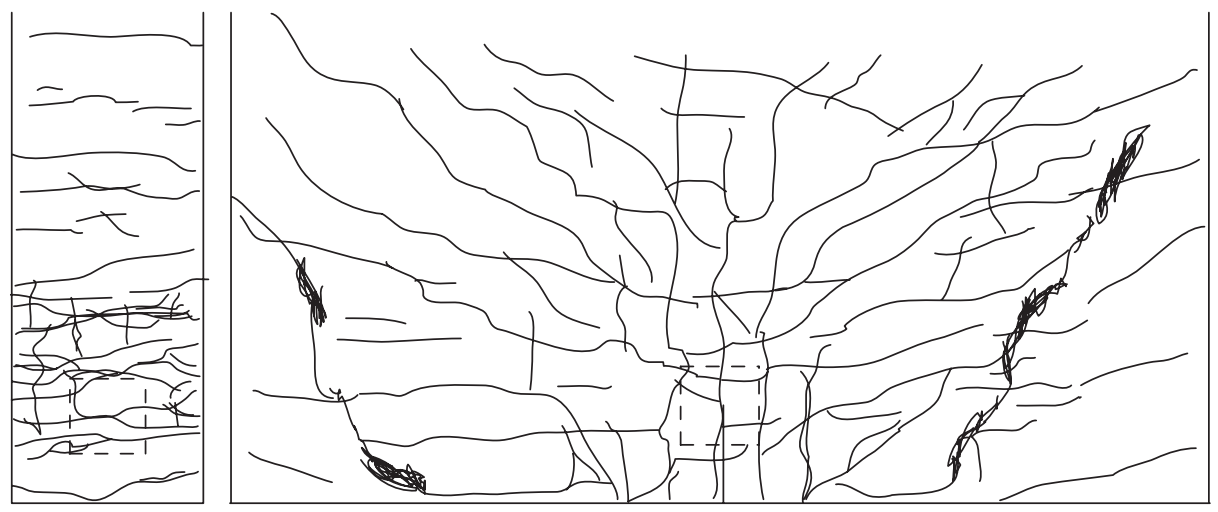

(c)

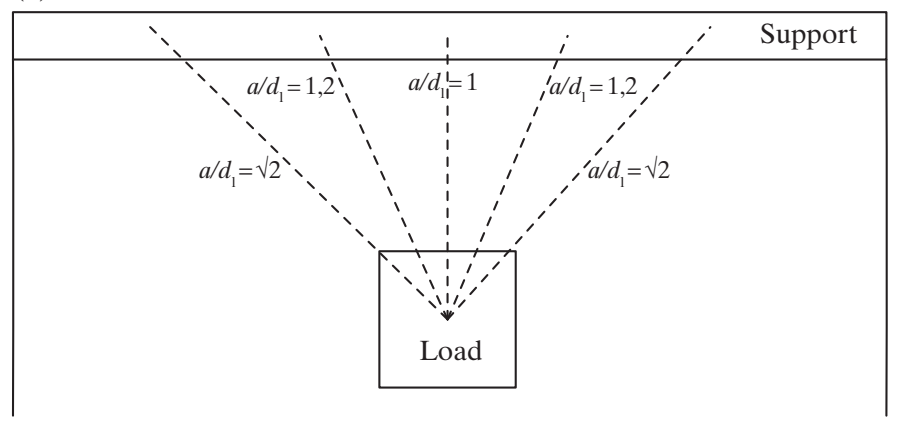

Fig. 4: Aspects of horizontal load distribution: (a) cracking pattern at the bottom face after an experiment on BS2; (b) cracking pattern at the bottom face after an experiment on S9, showing three-dimensional load-bearing behaviour. The dashed lines denote the location of the loading plate. Bold lines in (b) denote areas of punching damage; (c) fanning of compression struts leading to larger average a/d ratio for slabs as compared to beams

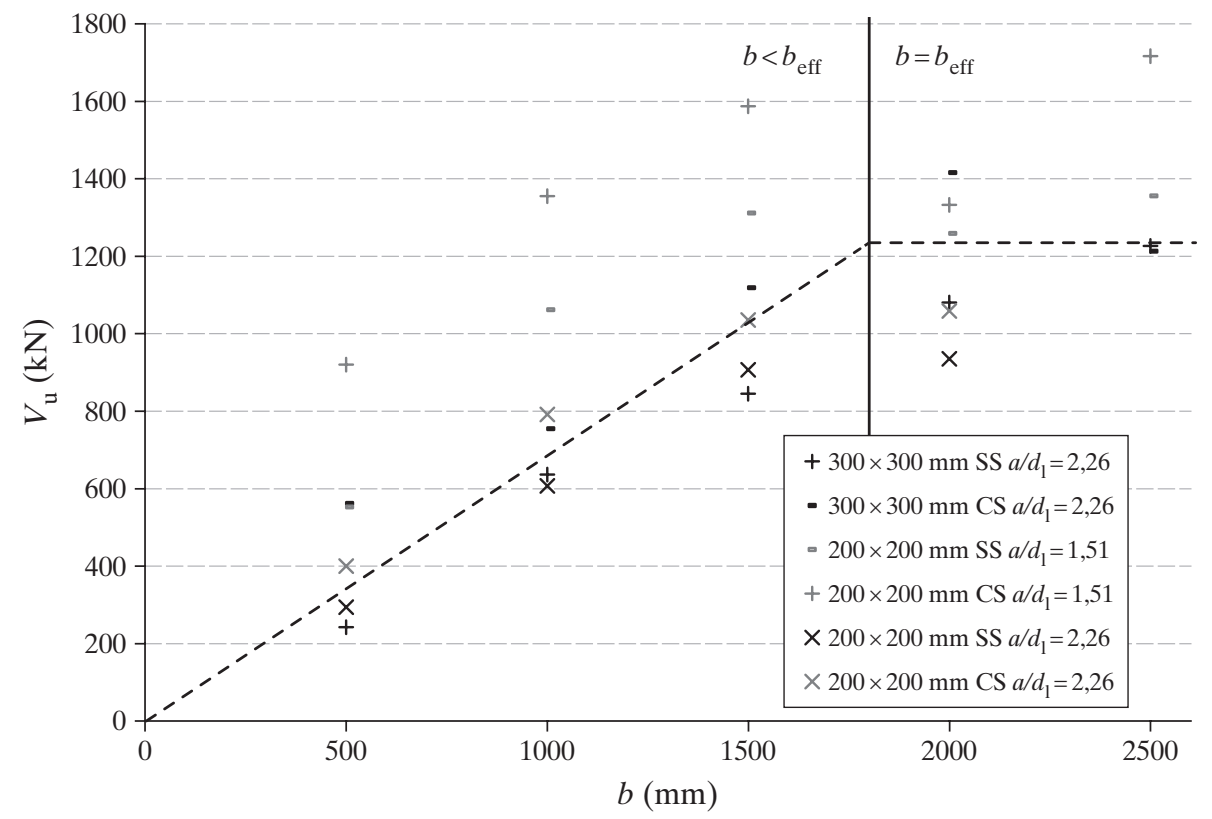

Fig. 5: Results for maximum sectional shear $V_{u}$ at the support in experiments on slab strips and slabs with $a$ width $b$ between 0,5 and $2,5 \mathrm{~m}$

The experimental results indicate that for slabs, the influence of the moment distribution over the support is smaller than for beams. The results of linear finite element calculations yield similar conclusions. This observation indicates no influence of cracking but solely the action of forces and moments. Hence, for slabs failing in shear the transverse explained on the basis of transverse load distribution. Considering the load distribution from the concentrated load towards the support in a slab as a three-dimensional problem, a larger loading plate provides a larger base for fanning out compressive struts. As these struts develop over a larger area, more material is activated to carry the load, thus increasing the shear capacity. For members with a smaller width, transverse load distribution cannot develop, and the size of the loading plate does not influence the member's capacity.

\section{Recommendations}

\section{Effective Width}

Slab and slab strips with a width between 0,5 and $2,5 \mathrm{~m}$ have been tested under six different loading conditions. The results are used to evaluate the horizontal load spreading methods (Fig. 1). According to the concept of the effective width, for slab strips with a small width an increase in the specimen width should lead to an increase in the shear capacity: the full specimen width carries the load at the support. For larger widths, a threshold value is expected above which no further increase in shear capacity is observed with an increasing specimen width. This threshold value corresponds to the effective width for shear, $b_{\text {meas }}$. The experimental results indeed show a threshold value (Fig. 5) that can be compared to the effective widths calculated on the basis of the load spreading methods. The results of this comparison are given in Table 2, in which $b_{\text {meas }}$, effective width as a threshold from the experiments; $b_{\text {eff1 }}$, effective width based on the Dutch load spreading method; $b_{\text {eff2 }}$, effective width based on the French load spreading method.

The results in Table 2 indicate that the effective width should be based on the French load spreading method. This method correctly takes into account the influence of the size of the load as well as the distance between the load and the support. It does not take into account the smaller effective threshold width that is observed at the continuous support as compared to the simple support.

In the next step, a statistical analysis is used to study which load spreading method should be used in combination with NEN-EN 1992-1-1.2 All experiments on slabs and slab strips under concentrated loads are analysed and 


\begin{tabular}{|l|c|c|c|c|c|}
\hline Series & $\begin{array}{c}\boldsymbol{b}_{\text {meas }} \\
(\mathbf{m})\end{array}$ & $\begin{array}{c}\boldsymbol{b}_{\text {eff1 }} \\
(\mathbf{m})\end{array}$ & $\begin{array}{c}\boldsymbol{b}_{\text {eff2 }} \\
(\mathbf{m})\end{array}$ & $\begin{array}{c}\boldsymbol{b}_{\text {meas }} / \boldsymbol{b}_{\text {eff1 }} \\
\text { Dutch }\end{array}$ & $\begin{array}{c}\boldsymbol{b}_{\text {meas }} / \boldsymbol{b}_{\text {eff }} \\
\text { French }\end{array}$ \\
\hline $300 \times 300 \mathrm{~mm}, \mathrm{SS}, a / d_{1}=2,26$ & 2,04 & 1,1 & 1,7 & 1,86 & 1,2 \\
\hline $300 \times 300 \mathrm{~mm}, \mathrm{CS}, a / d_{1}=2,26$ & 1,78 & 1,1 & 1,7 & 1,62 & 1,05 \\
\hline $200 \times 200 \mathrm{~mm}, \mathrm{SS}, a / d_{1}=1,51$ & 1,31 & 0,7 & 1,1 & 1,87 & 1,19 \\
\hline $200 \times \times 200 \mathrm{~mm}, \mathrm{CS}, a / d_{1}=1,51$ & 0,94 & 0,7 & 1,1 & 1,34 & 0,85 \\
\hline $200 \times 200 \mathrm{~mm}, \mathrm{SS}, a / d_{1}=2,26$ & 1,53 & 1,1 & 1,5 & 1,39 & 1,02 \\
\hline $200 \times 200 \mathrm{~mm}, \mathrm{CS}, a / d_{1}=2,26$ & 1,31 & 1,1 & 1,5 & 1,19 & 0,87 \\
\hline
\end{tabular}

Table 2: Effective width as calculated from the experimental results

\begin{tabular}{|l|c|c|c|c|}
\hline \multirow{2}{*}{} & \multicolumn{2}{|c|}{ Delft experiments } & \multicolumn{2}{c|}{ Slab shear database } \\
\cline { 2 - 5 } & $\boldsymbol{V}_{\mathbf{T U}} / \boldsymbol{V}_{\mathbf{E C}, \text { beff }}$ & $\boldsymbol{V}_{\mathbf{T U}} / \boldsymbol{V}_{\mathbf{E C}, \mathbf{b e f f 2}}$ & $\boldsymbol{V}_{\mathbf{d b}} / \boldsymbol{V}_{\mathbf{E C}, \text { beff1 }}$ & $\boldsymbol{V}_{\mathbf{d b}} / \boldsymbol{V}_{\mathbf{E C}, \text { beff2 }}$ \\
\hline Average & 3,401 & 2,382 & 1,937 & 1,57 \\
\hline Standard deviation & 0,89 & 0,522 & 1,228 & 0,659 \\
\hline Coefficient of variation & $26 \%$ & $22 \%$ & $63 \%$ & $42 \%$ \\
\hline
\end{tabular}

Table 3: Comparison between the shear capacity prescribed by the Eurocode 2 provisions ${ }^{2}$ and the experimental results

also the relevant experiments from the literature gathered in a slab shear database. ${ }^{16}$ The results are given in Table 3 , with $\mathrm{V}_{\mathrm{TU}}$, the ultimate shear force as observed in the Delft University of Technology experiments;

$V_{\mathrm{db}}$, the ultimate shear force from the slab database; $V_{\mathrm{EC} \text {,beff } 1}$, the shear force as calculated from the Eurocode 2 provisions $^{2}$ using the Dutch load spreading method, and $V_{\mathrm{EC} \text {,beff2, the shear }}$ force as calculated from the Eurocode 2 provisions $^{2}$ using the French load spreading method.

The analysis shows that both approaches lead to conservative results. However, the analysis in Table 3 clearly indicates that the French load spreading method is to be preferred as it leads to a smaller underestimation of the capacity and a smaller coefficient of variation.

On the basis of the experimental results and the statistical analysis, the French load spreading method can be identified as the preferred method for the effective width in shear.

The French load spreading method can be applied to the wheel loads in Load Model 1 from NEN-EN 1991-2 ${ }^{1}$ (Fig. 2), for which the effective width is determined per axle. For the axles in the first lane, an asymmetric effective width can be used with the edge distance limiting the effective width at the edge.

Finally, a minimum value for the effective width needs to be determined. For the experiment with the load near the edge and $a_{v}=200 \mathrm{~mm}$, a minimum effective width of $4 d_{1}$ can still safely be applied in combination with NEN-EN $1992-1-1 .^{2}$

\section{Transverse Load Distribution}

To take into account the higher shear capacities of slabs as compared to beams by virtue of transverse load distribution, an enhancement factor is proposed. This factor can be used to reduce the contribution of the concentrated loads to the total shear force. ${ }^{5}$ A comparison between experimental results and NEN-EN 1992-1$1^{2}$ with an effective width based on the French load spreading method results in a characteristic value $(5 \%$ lower bound assuming a normal distribution) for the enhancement factor of at least 1,25 for loads close to the support. For loads placed at a clear shear span $a_{v}>2,5 d_{1}$ no experimental evidence for the enhancement factor could be found in the slab shear database. $^{16}$

NEN-EN 1992-1-1² prescribes the use of a reduction factor for direct load transfer for loads close to the support as $\beta=a_{v} / 2 d_{1}$. Since the enhancement factor for concentrated loads on slabs is also applicable in the vicinity of the support, these factors can be combined into $\beta_{\text {new }}=a_{v} / 2,5 d_{1}$ with $0,5 d_{1} \leq a_{v} \leq$ $2,5 \mathrm{dl}$.

\section{Superposition of Loads}

The goal of the experiments under a combination of loads (S19-S25) is to verify the hypothesis of superposition as sketched in Fig. 6a. If this hypothesis is valid, then the sum, $\tau_{\text {combination }}$, of the shear stress due to the concentrated load over the effective width, $\tau_{\text {conc }}$, and the shear stress due to the distributed load at failure over the full width, $\tau_{\text {line }}$, should be at least equal to the ultimate shear stress in an experiment with a concentrated load only, $\tau_{\text {totcl. }}$. If the hypothesis of superposition is valid, the wheel load can be distributed per axle over the effective width associated with this axle and combined with the contribution of the dead load and lane load over the full width of the bridge.

In Fig. $6 b$, the results of the experiments with a combination of loads are compared to the results of a similar experiment with a concentrated load only. There is a difference in the cube compressive strengths of the concrete used in the experiments with multiple loads and the experiments with a concentrated load only (Table 1) because the age of testing was not the same. Therefore, $\tau_{\mathrm{tot}, \mathrm{cl}}$ is multiplied by the cube root (as used in NEN-EN 1992-1-12) of the ratio between the compressive strength of the specimen loaded with a concentrated load only $f_{\mathrm{c}}^{\prime}$, conc and the specimen loaded with a concentrated load and a line load $f_{\mathrm{c}, \text {, combi }}$ :

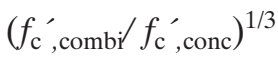

Equation (1) leads to the results denoted "compare, corr" in Fig. $6 b$. These results confirm the hypothesis of superposition. Typically, higher shear stresses are attained when combining different loads. When considering 36 cubes tested in compression at an age of 28 days for $\mathrm{C} 28 / 35$ concrete, a standard deviation of 3,68 MPa and a coefficient of variation of $8,5 \%$ are found. Two cases of slabs under a combination of loads, corrected for the difference in concrete compressive strength, result in a lower shear capacity than for a concentrated load only. This scatter, however, lies within the bandwidth resulting from the scatter on the material properties.

\section{Influence of Yield Strength of Reinforcement}

NEN-EN 1992-1-12 defines a lower bound for shear at which flexural failure will govern over shear failure. Yielding of the longitudinal reinforcement at a characteristic yield strength $f_{\mathrm{yk}}=500 \mathrm{MPa}$ was assumed for the derivation of this lower bound. ${ }^{17}$ For existing bridges in the Netherlands, often lower yield strengths are found. Before 1962, the standard reinforcement in the Netherlands was of the type "QR22" $\left(f_{\mathrm{yk}}=220 \mathrm{MPa}\right)$ or 
(a)

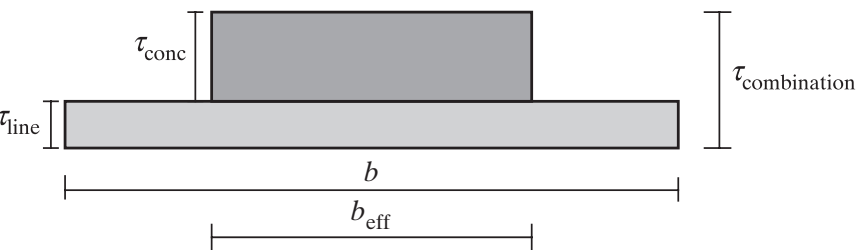

(b)

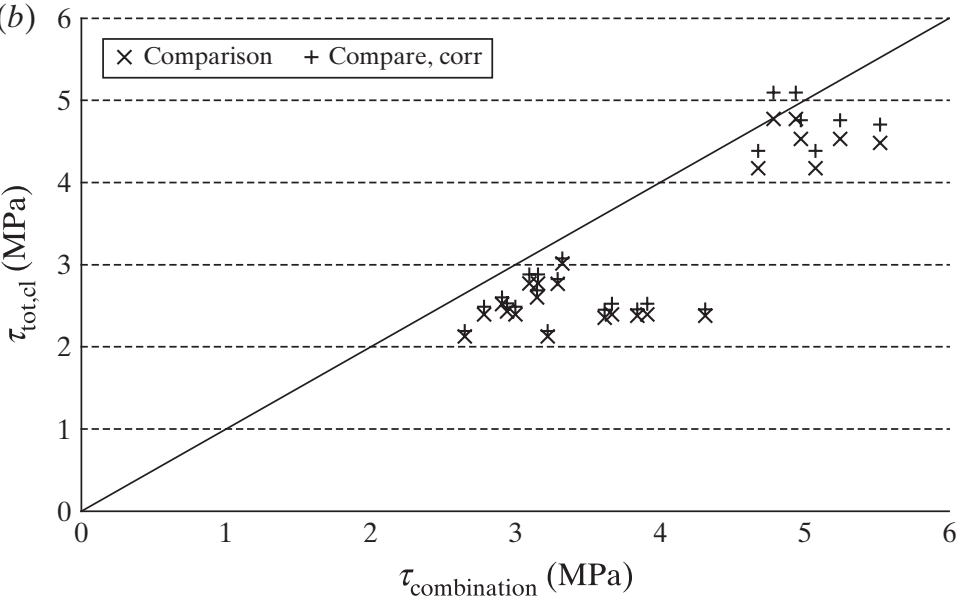

Fig. 6: Hypothesis of superposition: (a) Principle of superposition (b) Experimental results comparing the shear capacity at the support due to a concentrated load only, $\tau_{t o t, c l}$, and due to a combination of a concentrated load and a line load, $\tau_{\text {combination }}$

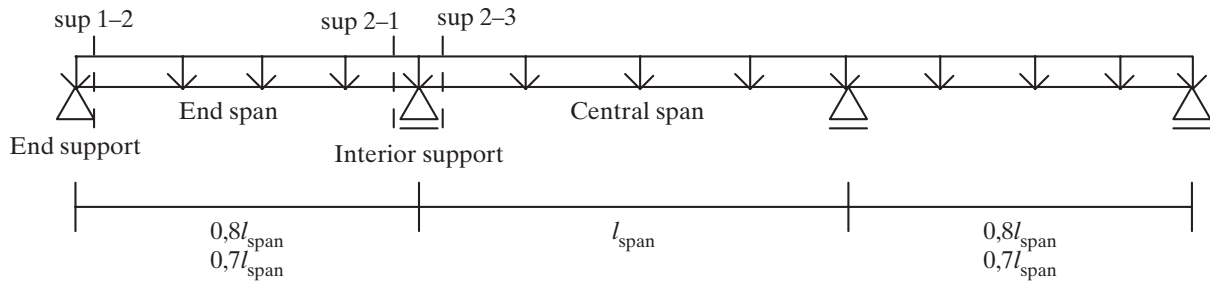

Fig. 7: Considered cross sections in a typical three-span bridge with mid-span length $l_{\text {span }}$

"QR24" ( $\left.f_{\mathrm{yk}}=240 \mathrm{MPa}\right)$. To leave out the assumption of $f_{\mathrm{yk}}=500 \mathrm{MPa}$, the expression for $v_{\min }$ can be derived as a function of $f_{\mathrm{yk}}$ :

$v_{\min }=0,772 k^{3 / 2} f_{\mathrm{ck}}^{1 / 2} f_{\mathrm{yk}}^{-1 / 2}$

with $f_{\mathrm{ck}}$, the characteristic cylinder concrete compressive strength; $k=1+\sqrt{200 / d_{1}} \leq 2,0$, the size effect factor.

\section{Resulting Improved QS-EC2}

\section{Application of Recommendations}

The recommendations from the experiments are applied to the QS-VBC, which was originally developed on the basis of the Dutch NEN $6720{ }^{3}$ In a full assessment, a shear check should be carried out at every cross section. Three cross sections at the face of the support for a continuous bridge are checked (Fig. 7). These locations are governing for shear in solid slab bridges with a constant cross-sectional depth. centre distance between the support and the tyre contact area; $b_{\text {load }} \times l_{\text {load }}$, width and length of the tyre contact area; $b_{\text {effi,j, }}$, effective width; $b_{\text {edge, }}$ the width of the edge of the viaduct; $i, 1$ ... 3 , corresponding to the considered truck; $j, 1 \ldots 2$, corresponding to the axle of the considered truck.

This effect is obtained by placing the first axle such that the face-to-face distance between the support and the tyre $a_{v}$ equals $2,5 d_{1}$. This load configuration is governing since $\beta_{\text {new }}$ from the set of recommendations takes the influence of direct load transfer and transverse load distribution into account up to $2,5 d_{1}$. In the second and third lanes, the design trucks are placed in such a way that the effective width associated with the first axle reaches up to the edge of the viaduct to maximise their effect on the shear force. This procedure is illustrated in Fig. 8 for the third axle (first axle of the second design truck). The second design truck is placed such that $b_{\text {eff2, } 1}$ just reaches the edge of the viaduct.

\section{Case Studies}

In an earlier version, the QS-VBC, the shear capacity was based on the design shear stress from NEN 6720:1995. ${ }^{3}$ In QS-EC2 the recommendations are combined with the shear capacity from NEN-EN 1992-1-1.2 In total, nine existing solid slab bridges having insignificant skew angles, with at least three spans and an (almost) constant cross-sectional depth, are checked at minimum three different cross sections as shown in Fig. 7. The results are given in Table 4, with $b$, full width of the viaduct; $d_{1}$, effective depth to the longitudinal reinforcement; $l_{\text {span }}$, length of the span; $f_{\text {ck, cube }}$, cube compressive strength of the concrete: based on core measurements or on the assumption of a minimum compressive strength of $45 \mathrm{MPa}$ when no results are available; $\rho_{1}$, amount of longitudinal reinforcement; $\tau_{\mathrm{d}}$, design shear stress at the support according to QS-VBC; $\tau_{\mathrm{u}}$, design shear capacity in QS-VBC; UC VBC, Unity Check based on QS-VBC, $\tau_{\mathrm{d}} / \tau_{\mathrm{u}}$; $v_{\mathrm{Ed}}$, design shear stress at the support according to QS-EC2; $v_{\mathrm{Rd}, \mathrm{c}}$, design shear resistance in QS-EC2; UC EC, Unity Check based on QS-EC2; $v_{\mathrm{Ed}}$ $v_{\mathrm{Rd}, \mathrm{c} \cdot}$

The shear stresses $\tau_{\mathrm{d}}$ and $v_{\mathrm{Ed}}$ can be compared to study the influence of the recommendations on the resulting design shear stress. In all cases, the recommendations have resulted in a 


\begin{tabular}{|c|c|c|c|c|c|c|c|c|c|c|c|}
\hline Section & $b(\mathrm{~m})$ & $d_{1}(\mathrm{~m})$ & $l_{\text {span }}(\mathrm{m})$ & $f_{\text {ck, cube }}$ (MPa) & $\rho_{1}(\%)$ & $\tau_{\mathrm{d}}(\mathbf{M P a})$ & $\tau_{\mathrm{u}}(\mathbf{M P a})$ & UC VBC & $v_{\mathrm{Ed}}(\mathrm{MPa})$ & $v_{\mathrm{Rd}, \mathrm{c}}(\mathrm{MPa})$ & UC EC \\
\hline $1 \sup 1-2$ & 9,6 & 0,791 & 9,5 & 45,0 & 0,443 & 0,35 & 0,66 & 0,52 & 0,27 & 0,45 & 0,60 \\
\hline $1 \sup 2-1$ & 9,6 & 0,791 & 9,5 & 45,0 & 0,517 & 0,49 & 0,66 & 0,74 & 0,40 & 0,47 & 0,85 \\
\hline 1 sup 2-3 & 9,6 & 0,791 & 13,0 & 45,0 & 0,517 & 0,52 & 0,66 & 0,78 & 0,45 & 0,47 & 0,95 \\
\hline $1 \sup 3-4$ & 9,6 & 0,791 & 15,5 & 45,0 & 0,583 & 0,58 & 0,66 & 0,88 & 0,52 & 0,49 & 1,05 \\
\hline $2 \sup 1-1$ & 14,5 & 0,331 & 7,0 & 45,0 & 1,045 & 0,70 & 0,66 & 1,07 & 0,53 & 0,72 & 0,75 \\
\hline $2 \sup 2-1$ & 14,5 & 0,331 & 7,0 & 45,0 & 1,045 & 0,92 & 0,66 & 1,40 & 0,72 & 0,72 & 1,00 \\
\hline $2 \sup 2-3$ & 14,5 & 0,331 & 8,4 & 45,0 & 1,045 & 0,90 & 0,66 & 1,36 & 0,73 & 0,72 & 1,02 \\
\hline $3 \sup 1-1$ & 11,9 & 0,6 & 7,1 & 58,3 & 0,429 & 0,39 & 0,79 & 0,49 & 0,28 & 0,53 & 0,52 \\
\hline $3 \sup 2-1$ & 11,9 & 0,6 & 7,1 & 58,3 & 0,429 & 0,52 & 0,79 & 0,66 & 0,40 & 0,53 & 0,75 \\
\hline $3 \sup 2-3$ & 11,9 & 0,6 & 8,4 & 58,3 & 0,429 & 0,51 & 0,79 & 0,64 & 0,40 & 0,53 & 0,76 \\
\hline $4 \sup 1-1$ & 11,9 & 0,36 & 7,1 & 70,6 & 0,716 & 0,63 & 0,92 & 0,69 & 0,45 & 0,73 & 0,63 \\
\hline $4 \sup 2-1$ & 11,9 & 0,36 & 7,1 & 70,6 & 0,716 & 0,83 & 0,92 & 0,91 & 0,62 & 0,73 & 0,85 \\
\hline $4 \sup 2-3$ & 11,9 & 0,36 & 8,4 & 70,6 & 0,716 & 0,81 & 0,92 & 0,88 & 0,63 & 0,73 & 0,87 \\
\hline $5 \sup 1-2$ & 13,6 & 0,542 & 9,5 & 48,4 & 0,817 & 0,53 & 0,69 & 0,77 & 0,44 & 0,62 & 0,72 \\
\hline $5 \sup 2-1$ & 13,6 & 0,542 & 9,5 & 48,4 & 0,909 & 0,72 & 0,69 & 1,04 & 0,63 & 0,62 & 1,02 \\
\hline $5 \sup 2-3$ & 13,6 & 0,542 & 12,5 & 48,4 & 0,909 & 0,73 & 0,69 & 1,05 & 0,64 & 0,62 & 1,04 \\
\hline 6 sup 1-2 & 19,2 & 0,457 & 1,0 & 49,6 & 0,934 & 0,63 & 0,71 & 0,89 & 0,53 & 0,67 & 0,78 \\
\hline $6 \sup 2-1$ & 19,2 & 0,457 & 1,0 & 49,6 & 0,934 & 0,84 & 0,71 & 1,19 & 0,72 & 0,67 & 1,08 \\
\hline $6 \sup 2-3$ & 19,2 & 0,457 & 13,0 & 49,6 & 0,934 & 0,87 & 0,71 & 1,23 & 0,74 & 0,67 & 1,10 \\
\hline $7 \sup 1-2$ & 14,8 & 0,54 & 9,5 & 37,3 & 0,77 & 0,52 & 0,58 & 0,90 & 0,44 & 0,55 & 0,79 \\
\hline $7 \sup 2-1$ & 14,8 & 0,54 & 9,5 & 37,3 & 1,284 & 0,71 & 0,58 & 1,22 & 0,61 & 0,66 & 0,92 \\
\hline $7 \sup 2-3$ & 14,8 & 0,54 & 14,0 & 37,3 & 1,284 & 0,77 & 0,58 & 1,32 & 0,68 & 0,66 & 1,04 \\
\hline $8 \sup 1-2$ & 13,4 & 0,59 & 12,0 & 66,4 & 1,366 & 0,53 & 0,87 & 0,60 & 0,44 & 0,80 & 0,55 \\
\hline $8 \sup 2-1$ & 13,4 & 0,59 & 12,0 & 66,4 & 1,573 & 0,73 & 0,87 & 0,84 & 0,64 & 0,84 & 0,76 \\
\hline $8 \sup 2-3$ & 13,4 & 0,59 & 15,1 & 66,4 & 1,573 & 0,73 & 0,87 & 0,84 & 0,64 & 0,84 & 0,76 \\
\hline $9 \sup 1-2$ & 12,5 & 0,65 & 1,0 & 74,6 & 0,55 & 0,45 & 0,96 & 0,47 & 0,37 & 0,77 & 0,48 \\
\hline 9 sup 2-1 & 12,5 & 0,65 & 1,0 & 74,6 & 1,092 & 0,63 & 0,96 & 0,66 & 0,54 & 0,77 & 0,70 \\
\hline $9 \sup 2-3$ & 12,5 & 0,65 & 15,0 & 74,6 & 1,092 & 0,69 & 0,96 & 0,72 & 0,61 & 0,77 & 0,79 \\
\hline
\end{tabular}

Table 4: Results of case studies: properties and results for verifications of cross sections according to $Q S$-VBC and QS-EC2

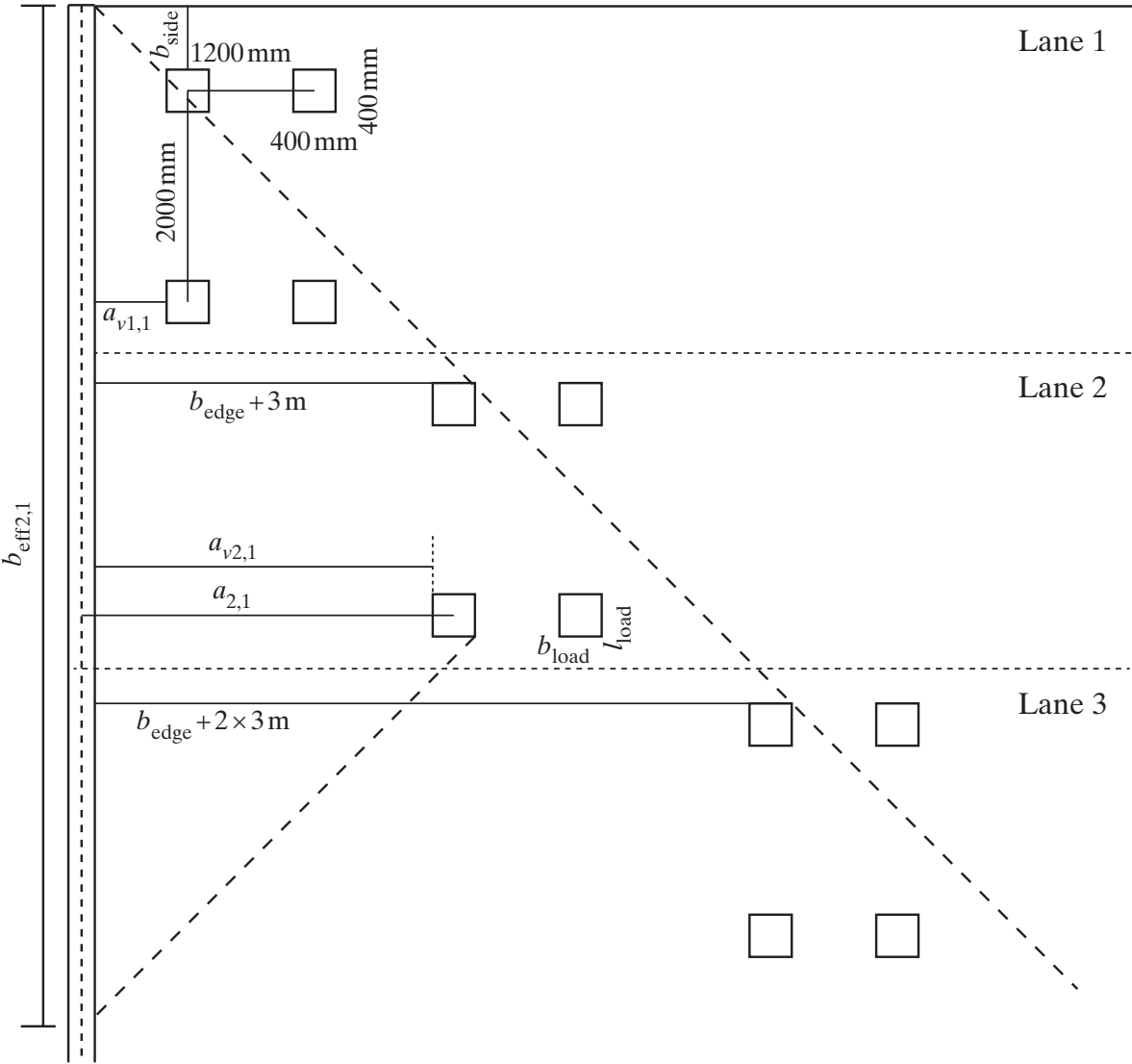

Fig. 8: Most unfavourable position of the design trucks for application in the Quick Scan method decrease in the shear stress as a result of the reduced contribution of the wheel loads.

The columns with $\tau_{\mathrm{u}}$ and $v_{\mathrm{Rd}, \mathrm{c}}$ can be used to compare the resulting shear capacities from NEN $6720^{3}$ and from NEN-EN 1992-1-1. ${ }^{2}$ It is confirmed that the recently implemented Eurocode is more conservative in shear, especially for low reinforcement ratios and deep cross sections. The value of $v_{\mathrm{Rd}, \mathrm{c}}$ is marked in blue when $v_{\min }$ (Eq. (2)) is governing.

The result of the implementation of the recommendations can be seen in the Unity Checks. Although the provisions for the shear capacity from NEN-EN 1992-1-1 ${ }^{2}$ are more conservative than those from NEN $6720,{ }^{3}$ the number of cross sections that do not meet the Unity Check criterion is reduced from nine with QS-VBC to seven with QS-EC2. If for limited or current use (with a smaller associated $\beta_{\text {rel }}$ value), Unity Check values exceeding by $10 \%$ can be allowed (dark red in Table 4) before more detailed calculations are required, only one section remains with QS-EC2, while according to QS-VBC 
six sections require a more detailed analysis. The recommendations have thus resulted in an improvement of the assessment practice and demonstrated the better selection ability of QS-EC2.

\section{Conclusions}

In the Quick Scan as developed by the Dutch Ministry of Infrastructure and the Environment, shear assessment is carried out at the "repair" level. To study the transverse redistribution capacity in slabs a series of experiments on half-scale continuous slab bridges were carried out. A new version, QS-EC2, based on the Eurocodes takes into account the results of experimental research:

- Use the French load spreading method for the effective width (Fig. 1b).

- Use a minimum effective width of $4 d_{1}$.

- For concentrated loads close to the support on slabs, the reduction factor from NEN-EN 1992-1-1 $\beta$ can be replaced by $\beta_{\text {new }}=a_{v} / 2,5 d_{1}$.

- The concentrated loads are distributed over their corresponding effective width and the distributed loads over the full width.

- The minimum shear capacity $v_{\min }$ is expressed as a function of the characteristic steel yield stress $f_{\mathrm{yk}}$.

These recommendations result in the most unfavourable position of the wheel loads with the first wheel load at a distance $2,5 d_{1}$ and the second and third truck in such a position that their influence on the shear stress near the edge is maximised.

A series of case studies on existing solid slab bridges shows the influence of the recommendations resulting in a decreased shear stress at the support and an improvement in the selection capacity of the "Quick Scan" sheet.

\section{Acknowledgements}

The authors wish to express their gratitude and sincere appreciation to the Dutch Ministry of Infrastructure and the Environment (Rijkswaterstaat) for financing this research work.

\section{References}

[1] CEN. Eurocode 1: Actions on StructuresPart 2: Traffic Loads on Bridges, NEN-EN 1991:2-2003, 2003; 168.

[2] CEN. Eurocode 2-Design of Concrete Structures: Part 1-1 General Rules and Rules for Buildings. NEN-EN 1992-1-1:2005, 2005; 229.

[3] Normcommissie 351001. Technical Fundaments for Construction Standards, Concrete Provisions TGB 1990 - Constructive Requirements and Calculation Methods (VBC 1995). NEN 6720:1995. Civil Center for the execution of research and standards, Dutch Normalisation Institute: Delft, The Netherlands, 1995; 245 (in Dutch).

[4] Walraven JC. Residual shear bearing capacity of existing bridges. fib Bulletin 57, Shear and punching shear in RC and FRC elements. Proceedings of a Workshop Held on 15-16 October 2010 Salo, Lake Garda, Italy, 2010; 129-138.

[5] Lantsoght EOL, van der Veen C, Walraven JC. Shear assessment of solid slab bridges. ICCRRR 2012, 3rd International Conference on Concrete Repair, Rehabilitation and Retrofitting, Cape Town, South Africa, 2012; 827-833.

[6] Reineck KH, Kuchma DA, Kim KS, Marx S. Shear database for reinforced concrete members without shear reinforcement. ACI Struct. J. 2003; 100(2): 240-249.

[7] Coin A, Thonier H. Essais sur le cisaillement des dalles en beton arme. Ann. batiment des travaux publics. 2007: 59: 7-16.

[8] Lantsoght EOL, van der Veen C, Walraven JC. Shear in one-way slabs under a concentrated load close to the support. ACI Struct. J. 2013;110 (2): 275-284.

[9] Lantsoght EOL, van der Veen C, Walraven J. Experimental study of shear capacity of reinforced concrete slabs. ASCE Structures Congress. Las Vegas, 2011; 12.

[10] Lantsoght EOL, van der Veen C, Walraven JC. Shear capacity of slabs and slab strips loaded close to the support. ACI SP-287, Recent Development in Reinforced Concrete Slab Analysis, Design and Serviceability, 2012; 5: 1-5.

[11] Cope RJ. Flexural shear failure of reinforced-concrete slab bridges. Proc. Inst.Civil Engs. Part 2-Res. Theory 1985; 79(SEP): 559-583.

[12] Normcommissie 351001. Assessment of Constructive Safety of an Existing Building at Repair Level and Unfit For Use - Basic Requirements, NEN 8700:2011. Civil Center for the execution of research and standards, Dutch Normalisation Institute: Delft, The Netherlands, 2011 (in Dutch).

[13] Normcommissie 351001. Assessment of Constructive Safety of an Existing Building at Repair Level and Unfit for Use - Loads, NEN 8701:2011. Civil Center for the execution of research and standards, Dutch Normalisation Institute: Delft, The Netherlands, 2011 (in Dutch).

[14] Steenbergen RDJM, Vrouwenvelder ACWM. Safety philosophy for existing structures and partial factors for traffic loads on bridges. Heron 2010; 55(2): 123-140.

[15] CEN. Eurocode - Basis of Structural Design, NEN-EN 1990:2002. 2002.

[16] Lantsoght EOL. Shear in Reinforced Concrete Slabs under a Concentrated Load Close to the Support. PhD Thesis, Delft University of Technology, 2013.

[17] Walraven JC. Background Document for EC-2, Chapter 6.2 Shear. Delft, The Netherlands: Delft University of Technology; 2002.

[18] Steenbergen RDJM, Vervuurt AHJM. Determining the in situ concrete strength of existing structures for assessing their structural safety. Struct. Conc. 2012; 13(1): 27-31.

\title{
Being a Member of IABSE brings you together...
}

\author{
Companies, \\ increase their access to visibility within the worldwide structural engineering community, \\ and to new information, new perspectives and new contacts.
}

..tell your colleague. 